\title{
Seasonal effects on fertility in gilts and sows
}

\author{
R. J. Love ${ }^{1}$, G. Evans ${ }^{2}$ and C. Klupiec ${ }^{1}$ \\ Departments of 'Animal Health and ${ }^{2}$ Animal Science, University of Sydney, NSW 2006, Australia
}

\begin{abstract}
The ancestral wild pig is a short day length seasonal breeder. The domestic pig appears to have retained some of this seasonality as evidenced by a reduction in fertility during the summer-autumn period. The most important aspect of this seasonality is a reduction in the number of mated sows that farrow. Many of these sows conceive and embryos develop normally for 20-25 days before pregnancy is terminated and the sow returns to oestrus (25-35 days after mating). In other species, transduction of photoperiodic information is achieved by release of melatonin during the dark period. In the pig, the pattern of melatonin secretion and the subsequent hypothalamo-pituitary-gonadal responses appear to be more complex. A relatively high light intensity is required for pigs to generate a distinct diurnal melatonin rhythm and they appear unable to respond appropriately to abrupt changes in photoperiod. Pigs on restricted feeding and maintained under long photoperiods (but not under short photoperiods) have higher concentrations of melatonin than do similarly maintained pigs fed ad libitum. Continuous release melatonin implants have a deleterious effect on farrowing rate, suggesting that the abnormally high melatonin concentrations observed in sows in summer-autumn play a role in the pathogenesis of seasonal infertility. Ad libitum feeding of sows during the first few weeks of pregnancy may prevent the increase in melatonin concentrations and so remove the seasonal influence on fertility. The pituitary response to different photoperiods is also somewhat confusing. Although there is some evidence of increased sensitivity to the negative feedback of ovarian steroids in the prepubertal gilts and weaned sows during summer-autumn, LH concentrations are increased in early pregnant sows. It is proposed that the failure of sows to maintain pregnancy in summer-autumn results from disruption of maternal recognition of pregnancy causing regression of the corpora lutea, loss of pregnancy and return of the sow to oestrus.
\end{abstract}

\section{Introduction}

The adverse seasonal effects on reproductive efficiency are of considerable economic significance to the pig industry worldwide. Efficient production requires a constant flow through the facility of growing pigs, and seasonal infertility in the summer-autumn period can dramatically disrupt this flow. A $10 \%$ reduction in the number of sows farrowing over 4 months is estimated to reduce profitability by $\$ A$ us 30 per sow per year (Cutler and Gardner, 1988). Decreases in productivity of this order or greater are not uncommon in Australia during the summer-autumn period.

It is now generally considered that photoperiod is the primary environmental cue to this seasonality and that the pig is essentially a short-day breeder. A considerable amount of research is being done to determine how pigs recognize and respond to changes in daylength. Current understanding of seasonal breeding stems largely from work in sheep, pronounced short-day breeders. The decreasing daylengths of late summer-autumn alter the diurnal profile of melatonin secretion and the duration of the period of 
high concentrations of melatonin associated with darkness. This changed profile reduces the negative feedback of oestradiol on the GnRH pulse generator allowing the development of an LH surge and ovulation. Use of the sheep as a model for pigs has revealed some similarities and many differences in the way pigs interpret and respond to changes in daylength and these will be discussed in this review.

\section{Seasonal Breeding in European Wild Boars}

In attempting to understand the seasonal reduction in reproductive efficiency, it is useful to refer to the studies of the clearly seasonal European wild boar, from which the domestic pig is largely derived.

European wild boars are distinctly seasonal breeders, usually producing only one litter per year farrowed in the spring such that conditions in subsequent months are most conducive to the survival of both the sow and her progeny (Mauget, 1982). The rut or breeding season producing this litter occurs in late autumn-early winter; the timing of commencement of the rut is very much influenced by food availability. A plentiful supply of mast (nuts from forest trees such as the beech and oak) is associated with early breeding activity. Farrowing is followed by a long lactation of about 3 months during which the sow remains in anoestrus. Weaning is a gradual process and lactation normally ceases in mid- to late summer and the anoestrous state continues after weaning until the next rut. Wild sows can produce two litters per year if lactation is terminated by removal or death of the litters before midsummer. However, sows weaning a litter after the summer solstice are unlikely to come into oestrus and will remain in anoestrus until late autumn (Mauget, 1982). An interesting aspect of reproduction in wild boars is the synchrony of oestrous activity that occurs within any group of sows at the start of the breeding season. This occurs in the absence of the boar, indicating that there are significant interactions within the sow group (probably pheromonal) that affect reproductive activity (Delcroix et al., 1990). The association of boars with a sow group is distinctly different from domestic arrangements. The boars are essentially solitary animals and only loosely and temporarily associated with a group of four or five sows at any time of the year (Signoret, 1980).

Domestic pigs are generally considered to be genetically remote from their wild ancestors. It certainly is in those characters which have a high heritability and have been strongly selected for in domestication (for example growth rate and carcass characteristics). However, there has been little deliberate selection pressure to negate the seasonal breeding pattern, because it has not been necessary. It is possible to take the wild pig producing one litter a year and convert her to a sow producing more than two litters per year simply by management practices normally used with domestic pigs. The most important practices are: (1) abrupt early weaning: as described above, the wild sow can produce two litters per year, even in the wild, if the litter is removed early in the lactation period; (2) the enforced presence of the boar and his influence on gilts approaching puberty and on sows at weaning: elimination of the boar influence by rearing gilts in the absence of boars to what is normally postpubertal age (Paterson et al., 1991) or by ablation of the olfactory bulbs of sows (Booth and Baldwin, 1983) renders these animals much more responsive to seasonal influences; (3) provision of high levels of nutrition throughout the year: the commencement of the breeding season in late autumn is very much influenced by feed availability; when feed is plentiful, breeding commences some months earlier (Mauget, 1982).

\section{Seasonal Infertility in Domestic Pigs}

It is not surprising to see evidence of the propensity towards seasonal breeding in domestic pigs manifest as a moderate decrease in fertility during the period of the year when pigs under natural conditions would not be breeding at all. This seasonal infertility is reported to have a variety of manifestations: delayed puberty in gilts, prolonged interval from weaning to oestrus in sows, failure of mated sows to farrow and reduction in number of piglets born per litter.

\section{Delayed puberty in gilts}

There is some confusion in the literature about the effect of season on puberty. However, most reports indicate that puberty is delayed during the summer period (reviewed by Hughes 1982). The effect 
on puberty is much more evident in the absence of boars. The intimate and continuous association of the boar, as occurs with domestic gilts, masks the innate seasonal breeding activity (Paterson et al., 1991). In the many studies on the boar effect on puberty, the effect of season has been largely ignored but application of practices developed from these studies dramatically reduces the adverse effects of season on attainment of puberty.

\section{Prolonged weaning to oestrus intervals}

The literature on increased weaning to oestrus intervals during summer and autumn has been reviewed by Claus and Weiler (1985). During summer and autumn, most sows have a normal weaning to oestrus interval. A minority of sows (most evident in the parity one group) have a considerably prolonged weaning to oestrus interval (>30 days) and this increases the mean figure (Hurtgen et al., 1980; Mattioli $e$ al., 1987). The minority group of sows essentially behaves like its wild counterpart, in which weaning during the summer and autumn is followed by a prolonged period of anoestrus (Mauget, 1982). In Australia, this is a relatively minor component of the seasonal infertility complex. The importance of this manifestation of seasonal infertility has declined as weaning age has been reduced (3-4 week weaning), boar influence on the weaned sow has been optimized and feeding levels of sows during lactation and in the weaning to oestrus period have increased. The condition of the sow at weaning, reflecting the level of feeding during the previous pregnancy and lactation, influences the interval from weaning to oestrus (reviewed by Aherne and Kirkwood, 1985) at any time of the year, but it becomes critical during the summer-autumn period.

\section{Reduced farrowing rate}

The reduction in the proportion of mated sows that farrow is currently by far the most important aspect of the seasonal infertility. The annual farrowing rate pattem in a 3000 sow intensive piggery (Fig. 1) shows that farrowing rate is reduced for 16 weeks after the summer solstice. The most common evidence of this problem is delayed ( $>24$ days) return to oestrus (usually 25 to 35 days after mating) as illustrated in Fig. 2 (Love, 1981; Reilly and Roberts, 1992). Sows at this time may show normal oestrous behaviour or may have an undetected oestrus and go through further oestrous cycles of normal duration (21 days) before being remated (Stork 1979; Love, 1981; Mattioli et al., 1987; Reilly and Roberts, 1992). Pregnancy losses also occur at later stages of pregnancy leading to the term 'autumn abortions' (Stork, 1979; Almond et al., 1985). There is evidence that some sows do not develop corpora lutea after mating. and remain in anoestrus (Williamson et al., 1980).

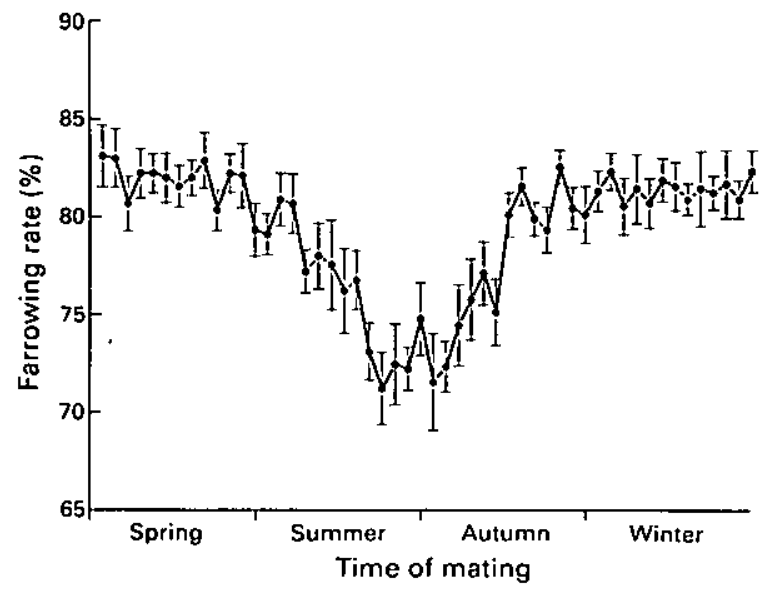

Fig. 1. Mean \pm SEM weekly farrowing rates for the period 1983-1991 for a 3000 sow intensive piggery. The sows are group housed from mating to farrowing. 


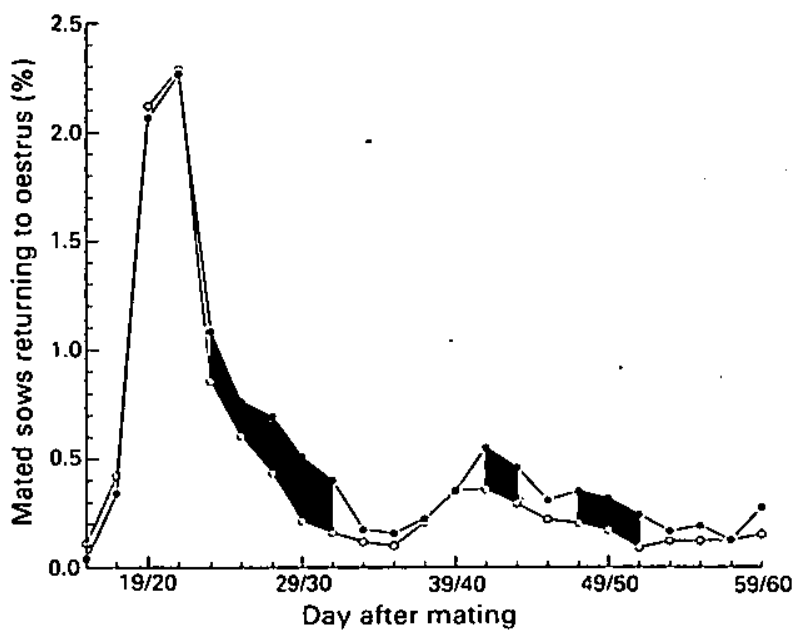

Fig. 2. Times of return to oestrus after mating for sows mated during (•) the period of seasonal infertility (weeks 1-15) or (o) during the remainder of the year (weeks 16-52). The number of sows returning for each two day interval was expressed as a percentage of the total sows mated in each period. The shaded area indicates where the two groups are significantly different $(P<0.05)$. Information was from a 3000 sow intensive piggery for the years 1987-1991.

It would seem that in a large proportion of sows showing delayed return to oestrus, fertilization occurs normally and viable embryos, as indicated by high concentrations of oestrone sulfate, are present 22-25 days after mating (Y. S. Pan, personal communication; Mattioli ef al., 1987). The stage of pregnancy when sows are found not to be pregnant depends on the efficiency of oestrus detection and timing and accuracy of pregnancy testing. When a doppler type ultrasound pregnancy detector (which detects the increased blood flow in the uterine arteries associated with pregnancy) was used carefully during the fifth week after mating during a severe seasonal infertility problem, all sows diagnosed as pregnant at that time, farrowed (Love, 1981). Use of A-mode ultrasound instruments (which detect fluid accumulation in the uterus) during the fifth week after mating can lead to a considerable overestimate of the pregnancy rate and erroneous conclusions about the time of pregnancy loss.

\section{Decreased litter size}

Reports on the effect on litter size resulting from matings during the summer and autumn vary from no effect (Love, 1978; Paterson et al., 1978; Mattioli $e t$ al, 1987) to significant reductions in litter size (reviewed by Claus and Weiler, 1985). The effect of season on litter size can be confounded by the increased number of return matings which result in larger litters (Love, 1978), as well as increased numbers of gilt matings producing smaller litters. Less stringent culling of older sows aimed at offsetting the reduction in fertility by increasing the numbers of matings may also affect average litter size.

\section{Photoperiod as the Environmental Cue to Seasonal Breeding}

There is only limited direct evidence connecting photoperiod with seasonal breeding activity in pigs. Claus and Weiler (1985) provided convincing evidence of the effect of photoperiod on boars in which changes in semen and plasma testosterone can be readily quantitated. Evidence for photoperiodic influence on females is less substantial. These authors used a decreasing day length programme in an 80 
sow piggery to simulate the natural decrease in autumn day length during summer. They demonstrated a reduction in interval from weaning to oestrus compared with the previous year in the same piggery.

Paterson and Pearce (1990), using controlled environment rooms, exposed prepubertal gilts from the vernal and autumnal equinox to photoperiods simulating the changes of summer and winter. In the absence of boar influence, puberty was inhibited in gilts exposed to the summer lighting regimen (only $3 \%$ reaching puberty by 225 days of age compared with $54 \%$ ). The presence of a boar overrode this photoperiodic effect. This work provides convincing evidence of the importance of photoperiod on this aspect of seasonal infertility.

\section{Transduction of Photoperiodic Information into Chemical Messenger}

In all species studied, photoperiodic information is transduced into an endocrine response by release of melatonin from the pineal gland which then influences the hypothalamic-pituitary-gonadal axis and hence reproductive activity. In species other than the pig, this signal is relatively simple: melatonin synthesis and secretion are increased during the scotophase (darkness) and decreased during the photophase (light) and the change in secretion is recognized by the hypothalamus (reviewed by Lincoln, 1992). However, there has been considerable confusion about the presence or absence of such a diurnal pattern of melatonin secretion in domestic pigs. Many researchers have been unable to demonstrate a nocturnal rise in melatonin (Brandt et al., 1986; Minton et al., 1989; Diekman et al., 1992); others have demonstrated such a rise only under equinoctial ( $12 \mathrm{~h}$ light:12 h dark) photoperiods and only in about half of the pigs studied (McConnell and Ellendorff, 1987; Minton et al., 1989) However, Paterson et al. (1992a) demonstrated consistent nocturnal rises in melatonin concentrations under short, equatorial and long photoperiods in prepubertal gilts. To add to the confusion, De Boer and Hacker (1986) found distinct and consistent increases in melatonin during daylight hours.

A number of factors have now been recognized that help to explain these variable results.

\section{Light intensity}

In humans there is an inverse linear relationship between light intensity and melatonin plasma concentrations during the photophase. The greater the suppression of melatonin in the light phase the higher the concentrations of melatonin during the dark phase (Lewy et al., 1980). Adequate light intensity is therefore critical to the generation of a distinct circadian rhythm of melatonin.

Griffith and Minton (1992) showed that a light intensity of 113 lux is insufficient to induce a circadian rhythm in melatonin in pigs. However, intense illumination (1783 lux) induced a clear rise in the scotophase melatonin concentrations indicating that light intensity is critical to entrainment of circadian rhythms. The critical light intensity has not been determined but reliable induction of a nocturnal melatonin rise would appear to require a light intensity of 200-300 lux. Paterson et al. (1992a), using 270 lux $400 \mathrm{~mm}$ above the floor, reliably induced nocturnal rises, whereas Minton and Cash (1990) using 202 lux $650 \mathrm{~mm}$ above floor level induced rises in only half of the pigs. Many of the lighting regimens used when investigating melatonin concentrations in pigs have involved intensities of less than 200 lux.

\section{Duration of photophase}

Pigs housed in continuous light (202 lux) or dark have a melatonin rhythm with a periodicity close to $24 \mathrm{~h}$ (Griffith and Minton, 1991). The pigs on continuous light have significantly higher concentrations of melatonin with much greater variability than those maintained in darkness.

Some studies have found equinoctial photoperiod regimens ( $12 \mathrm{~h}$ light: $12 \mathrm{~h}$ dark) to be effective inducers of nocturnal increases in melatonin concentrations (McConnell and Ellendorff, 1987; Minton and Cash, 1990), whereas short ( $8 \mathrm{~h}$ light:16 h dark) and long (16 h light: $8 \mathrm{~h}$ dark) photophases were ineffective (McConnell and Ellendorff, 1987). However, Paterson et al. (1992a) were able to demonstrate nocturnal rises in melatonin in short, equinoctial and long photophases. 


\section{Rate of change in photophase}

Most studies involving artificial lighting have used abrupt and extreme changes in photoperiod (from 8 to $16 \mathrm{~h}$ of light in one change). Paterson et al. (1992a) increased or decreased the photoperiod incrementally from $12 \mathrm{~h}$ light: $12 \mathrm{~h}$ dark mimicking the naturat rate of change in daylength and introduced the pigs into the controlled lighting conditions at the spring equinox. It is under these conditions that nocturnal increases in melatonin have been observed most consistently. As suggested by these authors, pigs may be unable to respond appropriately to sudden changes in photoperiod. In contrast, sheep show immediate and appropriate changes in melatonin when exposed to an abrupt change in photoperiod (Cutler, 1988).

\section{Season}

Exposure to natural light with the gradual decrease and increase in intensity at dusk and at dawn could provide quite a different stimulus to the on-off lighting situation that occurs in controlled environments used in many experiments. When early pregnant sows were exposed to natural light in an open-sided building, demonstrable nocturnal rises in melatonin during the night were seen only in spring and summer (Fig. 3). In this experiment the spring and autumn light periods would approximate $12 \mathrm{~h}$ light: $12 \mathrm{~h}$ dark, the summer $15 \mathrm{~h}$ light: $9 \mathrm{~h}$ dark and winter $9 \mathrm{~h}$ light: $15 \mathrm{~h}$ dark at this latitude. The other aspect of the melatonin profiles in this experiment was that overall concentrations in plasma were lowest in winter and highest in summer and autumn. Similar seasonal differences in melatonin concentrations were found by Peacock et al. (1991). The low winter concentrations of melatonin found were similar to those produced by pigs in continuous darkness (Griffith and Minton, 1991), and may reflect the lower light intensity during winter. However, the midday light intensity to which these sows were exposed was greater than 300 lux in mid-winter and was as high as could be achieved in housed pigs without exposure to direct sunlight. The high concentrations of melatonin in plasma in summer-autumn may also be similar to the higher concentrations observed under continuous illumination (Griffith and Minton, 1991).

\section{Physiological state}

Most studies investigating changes in melatonin concentrations have used young boars (Minton and Cash, 1990), castrates (Griffith and Minton, 1992) or gilts (Diekman et al., 1992; Paterson et al., 1992a). Others have used lactating sows (De Boer and Hacker, 1986), cyclic sows (McConnell and Ellendorff, 1987) or pregnant sows (Peacock et al. 1991). Nocturnal increases in melatonin have been demonstrated in at least one study in all these classes of pig except for the lactating sow. The lactating sow is remarkable in that daytime increases in melatonin were observed in sows and these were related to feeding (De Boer and Hacker, 1986).

\section{Age}

The amplitude of the nocturnal melatonin rise declines with age in rats (Pang et al., 1984) and humans (Waldhauser et al., 1988). Recent work in our laboratory has shown that distinct nocturnal increases in melatonin were more obvious in young pigs ( 7 weeks of age) than in prepubertal gilts or multiparous sows (C. Klupiec, R. Love and G. Evans, unpublished).

\section{Level of feeding}

The level of feeding affects melatonin secretion in species other than pigs. Three weeks of $50 \%$ feed restriction in rats caused increased scotophase melatonin concentrations (Chik et al., 1987) and complete deprivation in post-menopausal women caused a dramatic and immediate increase in daytime melatonin (Beitins et al., 1985). Diumal profiles were not determined in the latter experiment. Melatonin concentrations are also known to be considerably increased in anorexia nervosa and abnormal in other eating disorders in humans (Ferrari et al, 1989). Most of the experiments studying the melatonin concentrations in pigs have used various degrees of feed restriction (estimated as $60-80 \%$ of ad libitum intake). We 

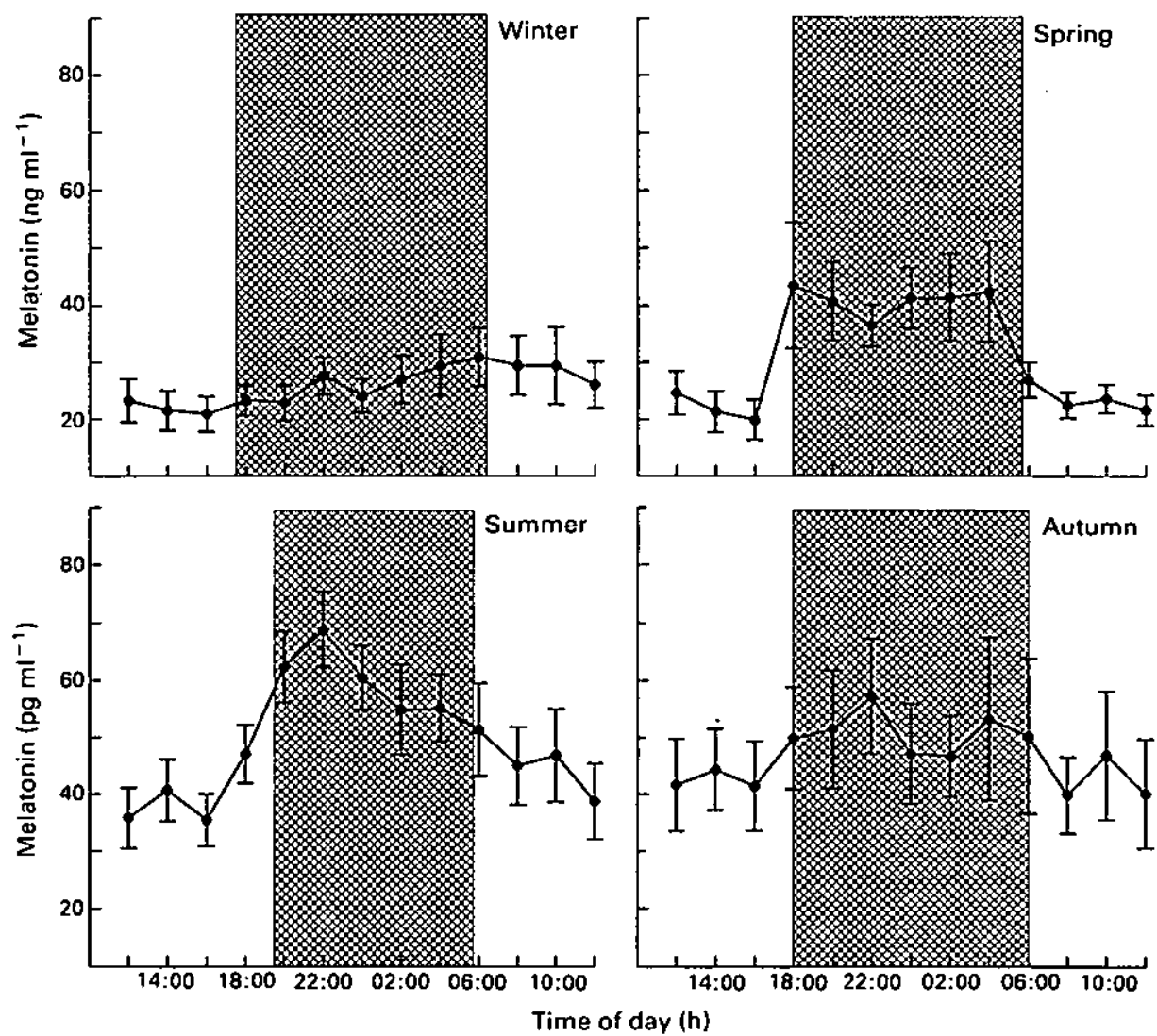

Fig. 3. Mean plasma melatonin concentrations for 4-week pregnant sows in the four seasons. Groups of eight sows exposed to natural lighting conditions were sampled at intervals of $2 \mathrm{~h}$ for $26 \mathrm{~h}$. The shaded areas represent the period from sunset to sunrise for each season.

examined the effect of a three week period of food restriction to $60 \%$ of ad libitum intake on $24 \mathrm{~h}$ melatonin profiles of prepubertal gilts on short $(9.5 \mathrm{~h})$ or long $(14.5 \mathrm{~h})$ photophases. Feed restriction caused a dramatic rise in melatonin concentration in pigs maintained under long photophase, but had no effect on pigs maintained under short photophase (Fig. 4). This finding could explain the higher melatonin concentrations in sows in summer-autumn, as pregnant sows have a restricted feed intake (usually about $60 \%$ of ad libitum intake). In commercial piggeries the amount of feed restriction is usually greatest for the first few weeks of gestation to minimize the adverse effects of 'overfeeding' on embryonic mortality and hence litter size.

In summary, it would appear that nocturnal increases in melatonin are most likely to occur in pigs maintained under high light intensities and fed ad libitum. Changes in the duration of the photophase should be incremental rather than abrupt to allow pigs to gradually alter their melatonin response.

\section{Seasonal Effects on the Hypothalamic-Pituitary-Ovarian Axis}

In sheep, distinctly short day breeding animals, changes in day length alter the activity of the GnRH pulse generator in the hypothalamus increasing or decreasing release of LH from the pituitary. Changes in photoperiod have both steroid-dependent and steroid-independent effects on GnRH release. Long photoperiods increase the sensitivity of the $\mathrm{GnRH}$ pulse generator to the negative feedback effects of oestrogens, markedly decreasing LH pulsatility. In the absence of ovarian steroids, long photoperiods have considerably less influence on LH pulsatility. 

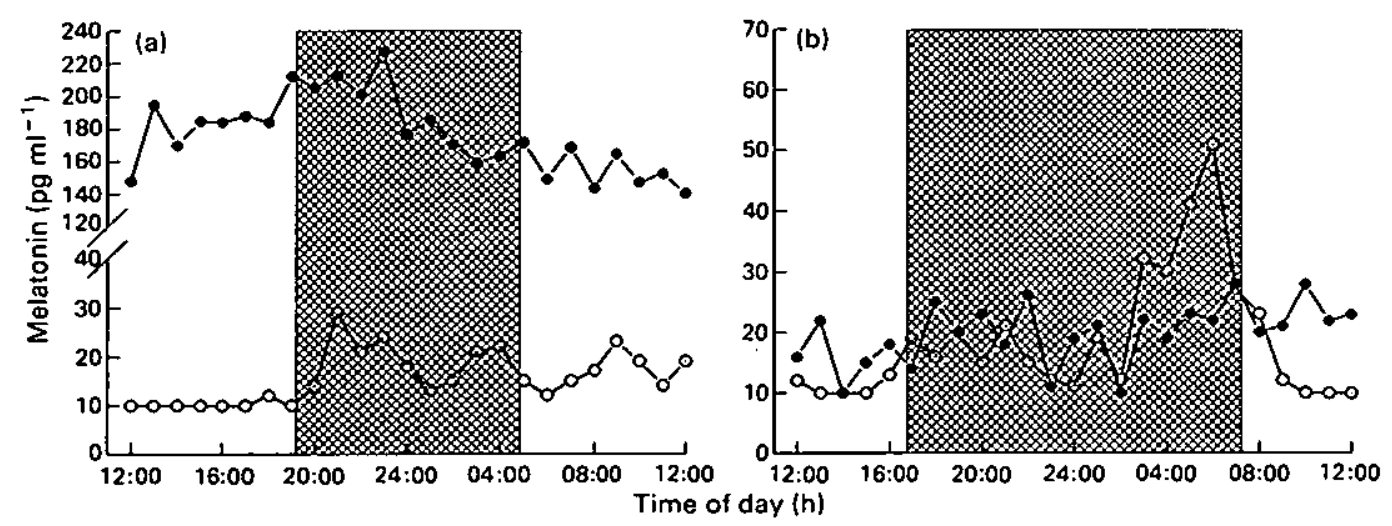

Fig. 4. Twenty-four hour profiles of concentration of melatonin in plasma in pairs of pigs of the (a) long photoperiod (14.5 h light:9.5 h dark) and (b) short (9.5 h dark:14.5 h light) photoperiod. Melatonin concentrations were determined while pigs were (o) ad libitum fed and ( $\bullet$ ) after 3 weeks of feed restriction to $60 \%$ ad libitum intake. The shaded areas indicate the periods of darkness.

There is evidence from pharmacological studies that both the catecholamine (Meyer and Goodman, 1985) and the endogenous opioid neurotransmitter systems (Ebling and Lincoln, 1985) are involved in the inhibition of $\mathrm{GnRH}$ secretion in sheep. Catecholamine inhibition is stronger during the non-breeding season, whereas the effect of endogenous opioids is greatest during the breeding season (Ebling and Hastings, 1992). The endogenous opioids function as part of the steroid feedback system; increasing endogenous opioid tone increases sensitivity to the negative feedback effect of the steroid suppression of GnRH secretion.

The precise mechanism by which the pattern of melatonin secretion, reflecting the changing photoperiod, influences GnRH release is not known (reviewed by Lincoln, 1992). In humans, acute melatonin treatment has been shown to block the LH rise induced by the endogenous opioid antagonist, naloxone (Esposti et al., 1988). However, the dosage of melatonin used may have produced pharmacological rather than physiological responses. Nevertheless, these results suggest that the endogenous opioid system plays a role in mediating the effects of melatonin. Whatever the mechanism, a period of 6-7 weeks exposure to a different photoperiod or melatonin supplementation is required for effects on reproductive activity to become evident (Karsch et al., 1984).

The experimental model that has been used extensively to study the seasonality of sheep is the ovariectomized ewe with or without oestradiol implants. In long-term ovariectomized ewes, LH pulses are relatively infrequent and of large amplitude during the long days of summer and become more frequent and of lower amplitude in winter. Oestradiol implants in ovariectomized ewes cause virtually complete suppression of LH pulsatility under long photoperiods but have little effect under conditions of short days (reviewed by Karsch et al., 1984). In ovariectomized pigs, Cox et al. (1987) found an increase in LH pulse amplitude and in baseline concentrations but no change in pulse frequency during summer compared with other seasons. However, Smith et al. (1991) could not demonstrate any such change with season.

Ovariectomized pigs maintained in controlled temperature environments and exposed to long photoperiods ( $16 \mathrm{~h}$ light: $8 \mathrm{~h}$ dark), had higher basal concentrations of LH but similar pulse frequency and amplitude to animals maintained on short photoperiods ( $8 \mathrm{~h}$ light:16 h dark) (Peacock, 1991). Chronic oestradiol implantation of ovariectomized pigs under these conditions reduced pulse frequency, amplitude and basal LH compared with non-implanted animals. The reduction in basal LH and pulse amplitude was significantly greater under short photoperiods ( $8 \mathrm{~h}$ light: $16 \mathrm{~h}$ dark), but pulse frequency was not significantly different (Peacock, 1991). It would appear that there are both steroid-independent and steroid-dependent effects of photoperiod on $\mathrm{LH}$ in ovariectomized sows as in ewes, but the effects are quite different. Rather than LH being reduced during the non-breeding season, it is actually increased without a change in pulse frequency. 
Intact, anoestrous, recently weaned sows have been shown to have lower hypothalamic GnRH content and lower concentrations of LH in the anterior pituitary in summer compared with sows weaned in winter. Serum $\mathrm{LH}$ concentrations were marginally lower at the time of weaning and $24 \mathrm{~h}$ later but were similar 48 and $72 \mathrm{~h}$ after weaning for the two groups of sows (Armstrong et al., 1986). These authors suggested that inadequate production of $\mathrm{GnRH}$ in summer led to postweaning anoestrus. An alternative interpretation of low hypothalamic GnRH and low pituitary $\mathrm{LH}$ could be that increased secretory activity depletes stores of these hormones.

Other studies have looked for differences between sows that have a normal post-weaning oestrus (less than 7 days after weaning) and sows that have a prolonged postweaning anoestrus. These seasonally anoestrous sows respond normally to pulsatile administration of GnRH (Armstrong and Britt, 1985), exogenous gonadotrophins (Dial et al., 1984; Britt et al., 1986) and exogenous oestrogen (Cox et al., 1983; Dial et al., 1984; Almond and Dial, 1990). Apparently the hypothalamic-pituitary-ovarian axis is fully functional, suggesting that alterations in the $\mathrm{GnRH}$ pulse generator are responsible for this seasonal anoestrus.

In early pregnant sows, mean plasma LH concentrations are higher in summer than in winter (Peacock, 1991; Smith and Almond, 1991). The LH profiles of sows in summer are very irregular compared with those in winter (Peacock, 1991) making estimates of pulse frequency difficult (Fig. 5). This pattern of LH secretion suggests a decreased response to the negative feedback effect of steroids. Concentrations of progesterone in plasma are marginally lower in the summer and autumn (Wrathall et al., 1986; Peacock, 1991), whereas concentrations of oestradiol in early pregnancy are apparently unaffected by season (Smith and Almond, 1991) and oestradiol is considered to be the more potent suppressor of LH secretion. lt therefore seems unlikely that reduced steroid concentrations are responsible for this increase in LH. Smith and Almond (1991) also showed that in early pregnant sows, release of LH in response to exogenous $\mathrm{GnRH}$ was not affected by season. Later in pregnancy, gilts had lower mean and baseline $\mathrm{LH}$ concentrations in summer than in winter and this was suggested as the cause of the autumin abortion syndrome'.

Despite the higher concentrations of LH in early pregnant sows during summer, plasma progesterone concentrations are lower at this time of the year (Wrathall et al., 1986; Peacock, 1991). These lower concentrations during summer may result from an increased rate of clearance of progesterone rather than from reduced secretion. Weaned sows cleared an intravenous bolus of progesterone more quickly in summer than during winter (Peacock, 1991).

The higher concentrations of $\mathrm{LH}$ in sows in early pregnancy during the summer period is difficult to reconcile with information from other seasonal breeders in which LH concentrations are decreased in the non-breeding season. It is conceivable that these high plasma concentrations of LH in sows during early pregnancy provide an inappropriate stimulus to ovarian receptors (causing downregulation), resulting in lower progesterone production and, in some sows, failure to maintain the corpora lutea.

The endogenous opioid system has been shown to be important in regulating hormones secreted by the adenohypophysis in many species. It appears that the endogenous opioids influence, or are an integral part of, the steroid-dependent feedback regulation of LH secretion (reviewed by Barb et al., 1991). $\beta$-Endorphin (Parvizi and Ellendorff, 1980) decreases LH secretion in pigs and naloxone, an opioid antagonist, in the presence of progesterone, causes a dramatic increase in both LH and prolactin (Barb et al., 1986). The increase in LH in early pregnant sows in summer could reflect a decrease in endogenous opioid tone, reducing the negative steroid-dependent feedback.

It may be that the unusually high concentrations of melatonin in plasma seen in sows during summer influence endogenous opioid tone and thus increase release of LH. In humans, melatonin supplementation has been shown to reduce $\mathrm{LH}$ (Voordouw et al., 1992) and the $\mathrm{LH}$ increase following naloxone infusion (Esposti et al., 1988). Although not consistent with the high melatonin-high LH findings in sows, this result does indicate that melatonin can influence the endogenous opioid system and $\mathrm{LH}$ secretion.

\section{Manipulation of Photoperiodic Response by Melatonin Supplementation}

The seasonal pattern of fertility in sows indicates that pigs, like sheep, are short day breeders. Administration of melatonin in the afternoon, prolonging the nocturnal rise in melatonin, or continuous release implants during summer, advances the onset of the breeding season in sheep (English et al., 1986). 


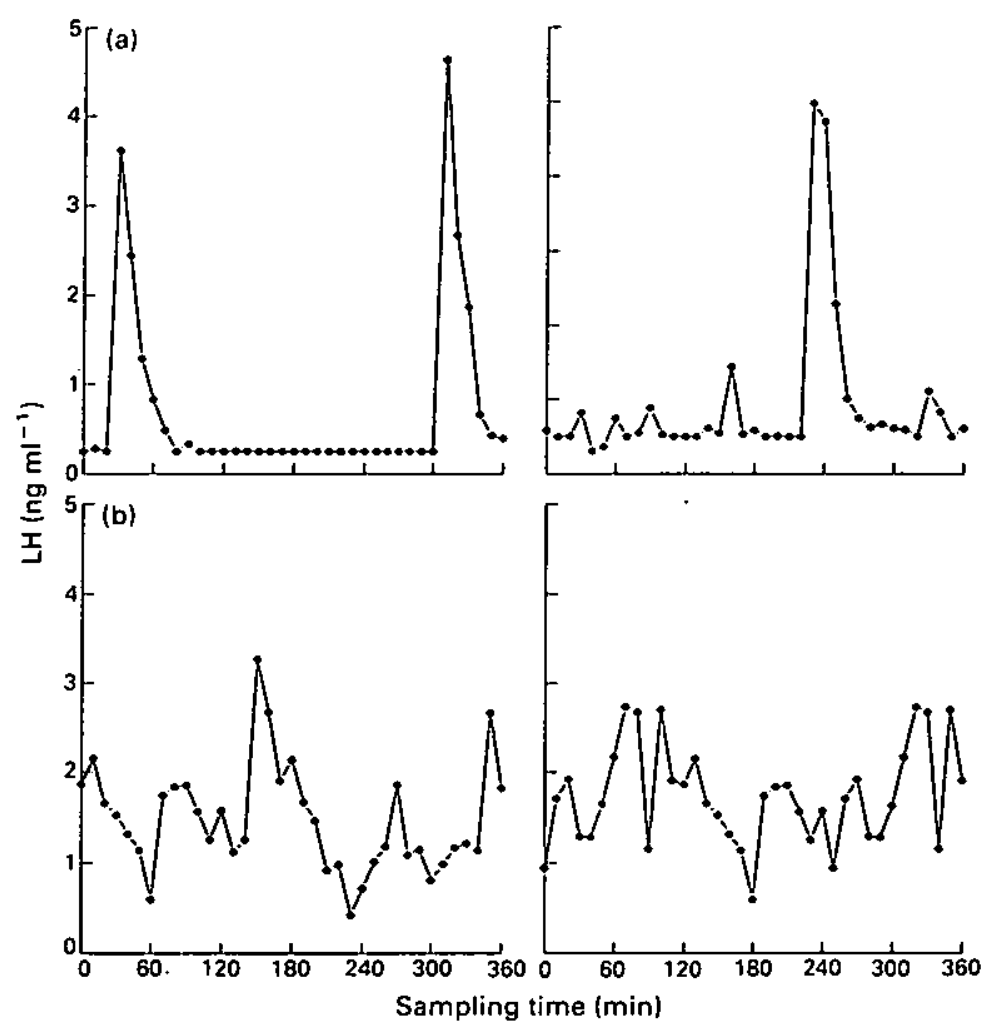

Fig. 5. Six hour profiles of plasma LH concentrations in two 4-week pregnant sows representative of (a) the winter period and (b) the summer period. Redrawn from Peacock (1991).

Afternoon in-feed administration of melatonin to prepubertal gilts from midsummer increased the proportion of gilts reaching puberty by 221 days of age ( $56 \%$ versus $24 \%$, Paterson ef al., 1992b). Diekman $e t$ al. (1991) found that daily melatonin supplementation increased the number of gilts reaching puberty in both autumn and spring. Inducing a marked nocturnal rise in concentration of melatonin in plasma appears to advance puberty in any season. The sustained increased concentration of melatonin following oral administration $(>8 \mathrm{~h}$ ) was similar to that reported for sheep and goats but was in contrast to work in humans in which only a transitory rise in melatonin plasma concentrations occurred (Wetterberg et al., 1977). The difference between the ruminants and humans was explained previously on the basis of retention of the oral dose in the rumen and gradual release to the lower intestinal tract for absorption (Kennaway and Seamark, 1980). Evidently the absorption of melatonin is different in the two aforementioned monogastrics.

Continuous release melatonin implants have no effect on the age at which gilts reach puberty during the summer-autumn period (Peacock et al., 1991; Paterson et al., 1992b). These implants have also been used in sows in an attempt to improve farrowing rate during the summer-autumn period. In this trial, half of the gilts were implanted 6 weeks before entry into the boar shed for mating; half the parity 1 sows were implanted at weaning approximately 4 weeks before mating (this parity group was mated at the second post-weaning oestrus); and half the older sows were implanted during the second week of lactation (approximately 3 weeks before the next mating). This implant regimen had no effect on the interval from weaning to oestrus or litter size but did have a significant deleterious effect on the farrowing rate in the more numerous older sow group (Table 1).

Sows during the summer-autumn period have been shown to have unusually high plasma melatonin throughout the $24 \mathrm{~h}$ period. These high concentrations may be involved in the pathogenesis of seasonal 
Table 1. The effect of continuous-release melatonin implants on fertility of gilts and sows during the summer-autumn period

\begin{tabular}{|c|c|c|c|c|c|c|}
\hline \multirow[b]{2}{*}{ Parameter } & \multicolumn{2}{|c|}{ Parity 1} & \multicolumn{2}{|c|}{ Parity $2^{2}$} & \multicolumn{2}{|c|}{ Parity $>2$} \\
\hline & Implant & Control & Implant & Control & Implant & Control \\
\hline Number of animals & 41 & 94 & 77 & 93 & 122 & 152 \\
\hline $\begin{array}{l}\text { Weaning to mating } \\
\text { interval (days) }\end{array}$ & - & - & $26.6 \pm 5.8$ & $26.8 \pm 6.5$ & $5.6 \pm 1.4$ & $5.3 \pm 1.3$ \\
\hline Farrowing rate \% & \multicolumn{2}{|c|}{$P=0.1065$} & \multicolumn{2}{|c|}{$P=0.1972$} & \multicolumn{2}{|c|}{$P=0.0097$} \\
\hline Litter size & $10.0 \pm 2.1$ & $9.6 \pm 2.8$ & $12.3 \pm 2.4$ & $11.6 \pm 3.1$ & $11.2 \pm 3.0$ & $11.5 \pm 3.1$ \\
\hline
\end{tabular}

Implants were placed six (parity 1), approximately 4 (parity 2) and approximately three (parity $>2$ ) weeks before mating.

This parity group was mated at the second oestrus after weaning.

infertility and hence in the adverse effect of the constant high concentration of melatonin produced by the implants. The failure of implants to adversely affect attainment of puberty in gilts or intervals from weaning to oestrus in sows suggests that pregnancy failure associated with seasonal infertility may have a different pathogenesis.

\section{Other Factors Interacting with Photoperiod}

If change in daylength per se was the cause of seasonal infertility, then the problem would be much more predictable thoughout the summer-autumn period. A feature of seasonal infertility is the extreme variability from piggery to piggery, from week to week within the same piggery (Love, 1981) and even from pen to pen of sows mated in the same week. It would appear that long daylengths are fundamental to inducing seasonal infertility and increase the sensitivity of the sow to other aspects of her environment. A number of factors may be responsible for this variability.

\section{Nutrition}

In wild boars, it appears that cessation of breeding activity is independent of the plane of nutrition but commencement of the breeding season is very dependent of food availability (Mauget, 1982, 1987). In domestic gilts many trials have been carried out to investigate the effect of various degrees of feed restriction on puberty (reviewed by Aherne and Kirkwood, 1985). The effect of season in which these trials have been conducted has largely been ignored and may explain the variable effect of feed restriction from delaying puberty to enhancing puberty. It may be that, like boar influence, ad libitum feeding may tend to negate the photoperiodic effect on puberty. The rat, a species considered unresponsive to photoperiod, is rendered responsive to photoperiod by feed restriction (Sorrentino et al., 1971).

It is well established that feeding level during lactation, or more precisely, excessive loss of body condition, extends the interval from weaning to oestrus (reviewed by Aherne and Kirkwood, 1985). Appetite is adversely affected by high temperatures and possibly also by season independent of temperature (Mauget, 1987), resulting in greater loss of body condition and extending the interval from weaning to oestrus.

Autumn abortions have been shown to be prevented by either increasing the temperature in the sow house or increasing feeding levels during autumn. The occurrence of abortions appeared to be unrelated to body condition and was considered to be associated with the increased energy demands of the cooler autumn months (Almond et al, 1985). 


\section{Social interactions}

The pig has an extremely well developed olfactory and vomeronasal system that can detect signalling and priming pheromones. It seems likely that there is a spectrum of pheromonal communication in pigs similar to that described in rodent species. In rodents there are both male-female and female-female pheromonal interactions (reviewed by Vandenbergh, 1983). The positive effect of boar pheromones on puberty in gilts and intervals from weaning to oestrus in sows is well known. More recently it has been shown that sows at oestrus have a stimulatory effect on weaned sows, inducing oestrus (Pearce and Pearce, 1992). The synchronous oestrous activity in European wild boars, in the absence of male influence, has been attributed to sow-sow interactions (Delcroix et al., 1990).

However, in addition to positive priming pheromones, a number of inhibitory pheromonal influences have been described in rodents. The most notable of these pertinent to domestic pigs are the effect of group size and crowding on attainment of puberty in young females and oestrous expression in mature females. These effects are most evident in the absence of males but are still expressed if the ratio of females to males is sufficiently high. The end result is determined by the balance between the stimulating effect of the males and the inhibitory influences of other females. This, together with other inhibitory pheromonal influences (e.g. dominant female on subordinate females), may act within the artificial population structure imposed on domestic pigs to affect reproductive success. For most of the year, the positive effects probably outweigh the negative influences except when reproductive impetus is at its lowest during the summer-autumn period.

Demonstration of such inhibitory social influences is logistically difficult in pigs. However, gilts exposed to urine collected from crowded gilts inhibited puberty in non-crowded gilts (Clark et al., 1985). suggesting that population density in pigs had similar effects to those demonstrated in rodents. Mixing of older pregnant sows with young newly mated sows under normal crowded conditions of domestication had an adverse effect on pregnancy rate in the younger sows, suggesting an effect of dominance on reproductive success (Wilson and Love, 1990).

Such apparently nebulous influences may explain the dramatic variation in the adverse effects of seasonal infertility on groups of sows. It is not unusual for a pen of 20 sows to achieve a farrowing rate of less than $50 \%$, while a second pen of sows mated in the same week and maintained in the same building have a normal farrowing rate. It appears that there are some group associated influences that determine reproductive success.

\section{Temperature}

Heat stress has been proposed by many as the cause of seasonal infertility (reviewed by Wettemann and Bazer, 1985). The strongest argument against heat stress playing a direct role in the pathogenesis of seasonal infertility is the timing of this problem. The period when seasonal infertility operates commences in midsummer and extends well into the autumn period when temperatures are very mild and certainly less severe than in the early summer period (Fig. 1). Provision of cooling in commercial piggeries has also failed to reduce the severity of seasonal infertility (Hurtgen and Leman, 1980). Rather than high environmental temperatures being involved, there is evidence that low temperatures or cold stress without an adequate compensatory increase in feeding level is responsible for the 'autumn abortion syndrome' (Almond et al., 1985). Sows can maintain pregnancy in midwinter on these relatively low feeding levels. It therefore appears that sows in this period are more sensitive to energy requirements than at other times.

\section{Housing}

Provision of individual stalls for mated sows significantly improves the farrowing rate during the summer-autumn period (Hurtgen and Leman, 1980). One large piggery in Australia has half its sows in stalls for the first few weeks of pregnancy and the other sows are maintained in groups of about 20; only the grouped sows show any evidence of seasonal infertility. There is also some evidence that group size is important, groups of five or six sows appear to be less affected by seasonal infertility than do large groups. It is not known how use of individual stalls reduces seasonal infertility: it may be a reduction in 
stress; it may ensure each sow receives an adequate level of nutrition; or it may be that use of individual stalls disrupts the group social interactions that have negative effects on fertility.

\section{The Effector Mechanism Disrupting Pregnancy}

Delayed puberty in gilts and anoestrus in sows have counterparts in other seasonal breeding species. However, the failure of sows to farrow that apparently ovulate normally and develop normal embryos into the fourth week of gestation is not a common reproductive strategy and appears to be a metabolically wasteful process. A similar phenomenon has been described in a tropical rodent (cloud forest mice) in coping with precarious food and water supplies. Mild restriction of either commodity in this species causes pregnancy failure and retum to oestrus (Heideman and Bronson, 1992).

It has been suggested that pregnancy failure in sows is the result of inadequate pituitary support (Wrathall et al., 1986). Once ovulation has occurred in pigs, the corpora lutea function autonomously for the first 14 days and it is only after this time that pituitary support, in the form of LH, is required (reviewed by Flint et al., 1982). Failure of adequate pituitary support at the time of transition of the corpora lutea to pituitary dependence fits well with the increased returns to oestrus 25-35 days after mating. In pregnant pigs with sectioned hypophyseal stalk, there was a gradual decline in corpus luteum function and death of embryos between 16 and 20 days after mating (Anderson et al., 1967).

Flushing embryos from the uterus 13 days after mating results in sows returning to oestrus 25-30 days after mating (van der Meulen et al., 1988). Persistence of the corpora lutea, necessary for the continuation of pregnancy, requires a second signal from the embryo in the period 15-30 days after mating. Killing the embryos at 22 days results in half the sows returning to oestrus and half remaining pseudopregnant (Love, unpublished observations), whereas death of the embryos at day 30 results consistently in pseudopregnancy (Webel $e$ t al., 1975). This second signal can be mimicked in nonpregnant sows by injection of oestradiol 15-20 days after oestrus (Geisert et al., 1987). Together with the evidence for biphasic production of oestrogens by embryonic tissues (Geisert et al., 1990), this finding indicates that the second signal is provided by oestrogens, but its mode of action has yet to be determined.

It seems more than coincidence that disruption of the second phase of the embryonic signal (required for the pregnant state to be maintained) results in return to oestrus at the same time as frequently occurs in seasonal infertility. Failure of the second embryonic signal could provide the basis for pregnancy failure in seasonal infertility. However, the presence of the viable embryos producing apparently normal concentrations of oestrone sulfate (Y. S. Pan, personal communication; Mattioli et al., 1987) suggests that, rather than a failure of production of this signal, there is a failure to respond to it. Such a hypothesis suggests that the function of the second signal is different from the first and may be, as suggested by Garverick $e t$ al. (1982), to increase LH receptors in the corpora lutea. Failure of maintenance of the corpora lutea could then result from inadequacy of the signal (removal of the embryos) or failure of effective occupancy of receptors (seasonal infertility), both situations resulting in delayed return to oestrus.

The unusually high concentrations of melatonin in plasma observed in early pregnant sows in summer-autumn during the period of seasonal infertility and the adverse effect of melatonin implants on farrowing rate suggest that these high concentrations are the cause of the pregnancy failures. High melatonin may exert its effect on LH secretion or, altematively, by direct effects on the ovary. High concentrations of melatonin occur only in pigs under long photoperiods when feed supply is restricted, if sows are therefore fed ad libitum during the summer-autumn period, melatonin concentrations will remain low and seasonal infertility not occur. Trials are being conducted to test this hypothesis by feeding sows liberally during the first four weeks of gestation.

Similar interactions between photoperiod and level of feeding have been described in male deer mice. These animals exhibit greater testicular regression in response to food restriction when maintained on short photoperiods than on long photoperiods (Nelson et al., 1992).

Sow diets are formulated to satisfy the nutrient requirements of the animal rather than appetite. Thus it has been suggested that sows spend much of each day hungry (Hutson, 1989) because they perceive that their food supply is inadequate. If the appetite of the sow is satisfied by feeding the same nutrients in a bulkier diet, there may be benefits to both sow welfare and productivity (Brouns and Edwards, 1992). 


\section{Conclusion}

It is clear that domestic pigs are seasonal breeders regulated primarily by photoperiod and seasonality is often manifest by a reduction in fertility in the summer-autumn period. Other environmental factors interact with photoperiod to potentiate or exacerbate the problem of summer-autumn infertility and, in early pregnant sows at least, nutrition may be the most potent of these factors. Although pigs behave as short-day breeders, transcription of environmental stimuli is not typical of a classic short-day breeder such as sheep. Melatonin concentrations are often highest during the infertile period and these are associated with, but not yet directly related to, higher mean LH concentrations. The mechanisms by which melatonin acts as a photoperiodic transducer, if indeed it does so in pigs, remain poorly understood.

The authors gratefully acknowledge the continuing financial support of the Australian Pig Research and Development Corporation amd the generous provision of the anti-LH serum by $\mathrm{G}$. Niswender. Without the interest and unstinting co-operation of R. G. Grey and Metro Farms Menangle in providing access to their records and pigs, our studies would not have been possible.

\section{References}

Aherne FX and Kirkwood R (1985) Nutrition and sow prolificacy Joumal of Reproduction and Fertility Supplement 33 169-183

Almond GW and Dial GD (1990) Estradiol feedback inhibition of luteinizing homone concentrations in the anestrous sow Journal of Animal Science 68 1077-1086

Almond GW, Friendship RM and Bosu WTK (1985) Autumn abortions in sows Canadian Veterinary Joumal $26162-163$

Anderson LL, Dyck GW, Mori H, Henricks DM and Melampy RM (1967) Ovarian function in pigs following hypophysial stalk transection or hypophysectomy American joumal of Physiology 212 1188-1194

Amstrong JD and Britt JH (1985) Pulsatile administration of gonadotropin-releasing hormone to anestrous sows: endocrine changes associated with $\mathrm{GnRH}$-induced and spontaneous estrus Biology of Reproduction 33 375-380

Armstrong JD, Britt JH and Cox NM (1986) Seasonal differences in function of the hypothalamic-hypophysial-ovarian axis in weaned primiparous sows Joumal of Reproduction and Fertility 78 11-20

Barb CR, Kraeling RR and Rampacek CB (1991) Opioid modulation of gonadotropin and prolactin secretion in domestic farm animals Domestic Animal Endocrinology 8 15-27

Barb CR, Kraeling RR, Rampacek GB and Whisnant CS (1986) Influence of stage of the estrous cycle on endogenous opioid modulation of luteinizing hormone, prolactin, and cortisol sectetion in the gilt Biology of Reproduction 35 1162-1167

Beitins IZ, Barkan A, Klibanski A, Kyung N, Reppart SM, Badger TM, Veldhuis J and McArthur JW (1985) Hormonal responses to short term fasting in postmenopausal women Joumal of Clinical Endocrinology and Metabolism 60 1120-1126

Booth WD and Baldwin BA (1983) Changes in oestrous cyclicity following olfactory bulbectomy in post-pubertal pigs Jounal of Reproduction and Fertility 67 143-150

Brandt KE, Diekman MA, Green ML and Malayer JR (1986) Lack of circadian rhythm in serum concentrations of melatonin in prepubertal gilts joumal of Animal Science 63 (Supplement 1) 356 (Abstract)

Britt JH, Esbenshade KL and Heller K (1986) Responses of seasonally anestrous gilts and weaned primiparous sows to treatment with pregnant mare's serum gonadotropin and altrenogest Theriogenology 26 697-707
Brouns F and Edwards SA (1992) Future prospects for housing of non-lactating sows Pig News and Information $1347 \mathrm{~N}-50 \mathrm{~N}$

Chik Cl, Ho AK and Brown CM (1987) Effect of food restriction on 24-h serum and pineal melatonin content in male rat Endocrinologica 115 507-513

Clark JR, Faillace LS, Tribble LF, Orr DE and Bell RW (1985) Effects of composition and density of the group and pheromone treatment on puberty in gilts reared in confinement Joumal of Reproduction and Fertility Supplement 33209 (Abstract)

Claus R and Weiler U (1985) Influence of light and photoperiodicity on pig prolificacy Joumal of Reproduction and Fertility Supplement 33 185-197

Cox NM, Esbenshade KL, and Britt JH (1983) Treatment of long-term anestrous sows with estradiol benzoate and GnRH: response of serum $\mathrm{LH}$ and occurrence of estrus Theriogenology 20 499-507

Cox NM, Ramirez JL, Matamoros 1A, Bennett WA and Britt JH (1987) Influence of season on estrous and luteinizing hormone responses to estradiol benzoate in ovariectomized sows Theriogenology 27 395-405

Cutler SAG (1988) Factors Involved in Photoperiodism in Ewes. PhD Thesis, University of Sydney

Cutler R and Gardner I (1988) A Blue Print for Pig Health Research. Pig Research Council. Canberra

De Boer $\mathrm{H}$ and Hacker RR (1986) Circadian rhythm of melatonin, thyroxine and prolactin in sows Canadian Joumal of Animal Science 661189 (Abstract)

Delcroix I, Mauget R and Signoret JP (1990) Existence of synchronization of reproduction at the level of the social group of the European wild boar (Sus scrofa) Joumal of Reproduction and Fertility 89 613-617

Dial GD, Bevier GW, Hixon JE and Gustafsson BK (1984) Endocrine pathogenesis of post weaning anestrus in swine: response of the persistently anestrous sow to hormonal stimuli American joumal of Veterinary Research 45 1737-1742

Diekman MA, Clapper JA, Green ML and Stouffer DK (1991) Reduction in age of puberty in gilts consuming melatonin during decreasing or increasing daylength joumal of Animal Science 69 2524-2531

Diekman MA, Brandt KE, Green ML, Clapper JA and Malayer JR (1992) Lack of a nocturnal rise of serum melatonin in prepubertal gilts Domestic Animal Endocrinology 9 161-167 
Ebling FP and Hastings MH (1992) The neural basis of seasonal reproduction Amales de Zootechnie 41 239-246

Ebling FP and Lincoln GA (1985) Endogenous opioids and the control of seasonal LH secretion in Soay rams joumal of Endocrinology 107 341-353

English J, Poulton AL, Arendt J and Symons AM (1986) A comparison of the efficiency of melatonin treatments in advancing oestrus in ewes Journal of Reproduction and Fertility 77 321-327

Esposti D, Lissoni P. Mauri R, Rovelli F, Orsenigo L, Pescia S, Vegetti G. Esposti G and Fraschini F (1988) The pineal gland-opioid system relation: melatonin-naloxone interactions in regulating $\mathrm{GH}$ and $\mathrm{LH}$ releases in man joumal of Endocrinological Investigation 11 103-105

Ferrari E, Foppa S, Bossolo PA, Comis S. Esposti G, Licini V, Fraschini $F$ and Brambilla $F$ (1989) Melatonin and pituitarygonadal function in disorders of eating behavior joumal of Pineal Research 7 115-124

Flint APF, Saunders PTK and Ziecik AJ (1982) Blastocystendometrium interactions and their significance in embryonic mortality. Control of Pig Reproduction, pp 253-276 Eds DJA Cole and GR Foxcroft. Butterworths, London

Garverick HA, Polge C and Flint APF (1982) Oestradiol administration raises luteal $\mathrm{LH}$ receptor levels in intact and hysterectomized pigs Joumal of Reproduction and Fertility 66 371-377

Geisert RD, Zavy MT, Wettemann RP and Biggers BG (1987) Length of pseudopregnancy and pattern of uterine protein release as influenced by time and duration of oestrogen administration in the pig loumal of Reproduction and Ferfility 79 163-172

Geisert RD, Zavy MT, Moffatt RJ, Blair RM and Yeilin T (1990) Embryonic steroids and the establishment of pregnancy in pigs Jountal of Reproduction and Fertility Supplement $\mathbf{4 0}$ 293-305

Griffith MK and Minton JE (1991) Free-nunning thythms of adrenocorticotropic hormone (ACTH), cortisol and melatonin in pigs Domestic Animal Endocrinology 8 201-208

Griffith MK and Minton JE (1992) Effect of light intensity on circadian profiles of melatonin, prolactin, ACTH, and cortisol in pigs Joumal of Animal Science 70 492-498

Heideman PD and Bronson FH (1992) A pseudoseasonal reproductive strategy in a tropical rodent, Peromyscus mudipes Joumal of Reproduction and Fertility 95 57-67

Hughes PE (1982) Factors affecting the natural attainment of puberty in the gilt. In Control of Pig Reproduction, PP 117-138 Eds DJA Cole and CR Foxcroft. Butterworths. London

Hurtgen JP and Leman AD (1980) Seasonal influence on the fertility of sows and gilts joumal of the American Veterinary Medical Association $177631-635$

Hurtgen JP, Leman AD and Crabo B (1980) Seasonal infuence on estrous activity in sows and gilts joumal of the American Veterinary Medical Association 176 119-123

Hutson GD (1989) Operant responding by sows on restricted rations for additional food. In Manipulating Pig Production II, p 213 Eds JL Bamett and DP Hennessy. Australian Pig Science Association, Albury

Karsch F). Bittman El. Foster DL, Goodman RL, Legan SJ and Robinson JE (1984) Neuroendocrine basis of seasonal reproduction Recent Progress in Hormone Research 40 185-232

Kennaway DJ and Seamark RF (1980) Circulating levels of melatonin following its oral administration or subcutaneous injection in sheep and goats Australian Joumal of Biological Sciences 33 349-353
Lewy AJ, Wehr TA, Goodwin FK, Newsome DA and Markey SP (1980) Light suppresses melatonin secretion in humans Science 210 1267-1269

Lincoln GA (1992) Photoperiod-pineal-hypothalamic relay in sheep Animal Reproduction Science 28 203-217

Love RJ (1978) Definition of a seasonal infertility problem in pigs Veierinary Record 103 443-446

Love RJ (1981) Seasonal infertility in pigs Veterinary Record 109 407-409

McConnell SJ and Ellendorff F (1987) Absence of nocturnal plasma melatonin surge under long and short artificial photoperiods in the domestic sow Joumal of Pineal Research $4201-210$

Mattioli M, Prandi A, Camporesi A, Simoni A and Seren E (1987) Investigations on swine summer infertility in Italy. In Definition of the Summer Infertility Problem in the Pig. pp 33-43 Eds E Seren and M Mattioli. Commission of the European Communities, Brussels

Mauget R (1982) Seasonality of reproduction in the wild boar. In Control of Pig Reproduction, pp 509-526 Eds DJA Cole and GR Foxcroft. Butterworths, London

Mauget R (1987) Reproductive biology of the European wild boar. In Definition of the Summer Infertility Problem in the Pig. pp 107-119 Eds E Seren and M Mattioli. Commission of the European Communities, Brussels

Meyer SL and Goodman RL (1985) Neurotransmitters involved in mediating the steroid-dependent suppression of pulsatile luteinizing homone secretion in anestrous ewes, effects of receptor antagonists Endocrinology 116 2054-2061

Minton JE and Cash WC (1990) Effect of cranial sympathectomy on circadian rhythms of cortisol, adrenocorticotropic hormone and melatonin in boars Joumal of Animal Science 68 4277-4284

Minton JE, Davis DL and Stevenson JS (1989) Contribution of the photoperiod to circadian variations in serum cortisol and melatonin in boars Domestic Animal Endocrinology 5 177-181

Nelson RJ, Kito M, Blom JMC and Rhyne-Grey J (1992) Photoperiod influences the critical calorific intake necessary to maintain reproduction among male deer mice (Peromysas maniculatus) Biology of Reproduction 46 226-232

Pang SF, Tang F and Tang PL (1984) Negative correlation of age and the levels of pineal melatonin, pineal n-acetylserotonin, and senum melatonin in male rats Jounal of Experimental Zoology 229 41-47

Parvizi $N$ and Ellendorf F (1980) $\beta$-Endorphin alters luteinizing homone secretion via the amygdala but not the hypothalamus Nature $286812-813$

Paterson AM and Pearce GP (1990) Attainment of puberty in domestic gilts reared under long-day or short-day artificial light regimens Animal Reproduction Science 23 135-144

Paterson AM, Barker I and Lindsay DR (1978) Summer infertility in pigs: its incidence and characteristics in an Australian commercial piggery Australian Joumal of Experimental Agriculture and Animal Husbandry 18 698-701

Paterson AM, Pearce GP and D'Antuono MF (1991) Seasonal variation in attainment of puberty in isolated and boarexposed domestic gilts Animal Reproduction Science 24 32.3-3.3.

Paterson AM. Martin GB, foldes A, Maxwell CA and Pearce GP (1992a) Concentrations of plasma melatonin and luteinizing homone in domestic gilts reared under artificial long or short days Journal of Reproduction and Fertility 94 85-95

Paterson AM, Maxwell CA and Foldes A (1992b) Seasonal inhibition of puberty in domestic gilts is overcome by 
melatonin administered orally, but not by implant Joumal of Reproduction and Fertility 94 97-105

Peacock AJ (1991) Environmental and Social Factors Affecting Seasonal Infertility of Pigs PhD Thesis, University of Sydney

Peacock AJ، Evans G and Love RJ (1991) The role of melatonin in seasonal infertility of pigs Advances in Pineal Research 6 189-198

Pearce GP and Pearce AN (1992) Contact with a sow in oestrus or a mature boar stimulates the onset of oestrus in weaned sows Veierinary Record 130 5-9

Reilly JD and Roberts AJ (1992) An investigation into summer infertility in a commercial pig unit Pig Velerinary Jounal 27 157-168

Signoret JP (1980) The effects of the male on female physiology. In Behaviour in Relation to Reproduction, Management and Welfare of Famn Animals, pp 23-27 Eds M WodzickaTomaszewska. TN Edey and jJ Lynch. University of New England, Amidale

Smith CA and Almond GW (1991) Effects of season and stoge of gestation on luteinizing hormone release in gilts Canadian joumal of Velerinary Research 55 294-297

Smith CA, Almond GW and Dial GD (1991) Effects of season and estradiol-17 $\beta$ on luteinizing hormone release in ovariectomized sows Jountal of Animal Science 69 4907-4913

Sorrentino S, Reiter RJ and Schalch DS (1971) Interactions of the pineal gland, blinding, and underfeeding on reproductive organ size and radioimmunoassayable growth homone Neuroendocrinology 7 105-111

Stork MC (1979) Seasonal reproductive inefficiency in large pig breeding units in Britain Veterinary Record 104 49-52

Vandenbergh JC (1983) Pheromonal regulation of puberty. In Pheromones and Reproduction in Mammals, pp 95-112 Ed JG Vandenbergh. Academic Press, New York

van der Meulen J, Helmond FA and Oudenaarden CPJ (1988) Effect of flushing of blastocysts on Day 10-13 on the life- span of the corpora lutea in the pig Joumal of Reproduction and Fertility 84 157-162

Voordouw BCG, Euser R, Verdonk ER, TH Alberda B. De Jong FH, Drogendijk AC, Fauser BCJM and Cohen $M$ (1992) Melatonin and melatonin-progestin combinations alter pituitary-ovarian function in women and can inhibit ovulation Joumal of Clinical Endocrinology and Metabolism 74 108-117

Waldhauser F, Weiszenbacher G, Tatzer E, Gisinger B, Waldhauser $M$, Schemper $M$ and Frisch $H$ (1988) Alterations in noctumal serum melatonin levels in humans with growth and aging Joumal of Clinical Endocrinology and Metabolism 66 648-652

Webel SK, Reimers TJ and Dziuk PJ (1975) The lack of relationship between plasma progesterone levels and number of embryos and their survival in the pig Biology of Reproduclion 13 177-186

Wettemann RP and Bazer FW (1985) Influence of environmental temperature on prolificacy of pigs Joumal of Reproduction and Fertility Supplement 33 199-208

Wetterberg L, Erikson O, Friberg $Y$ and Vangbo B (1977) A simplified radioimmunoassay for melatonin and its application to biological fluids: preliminary observations on the half-life of plasma melatonin in man Clinien Chimica Acta 86 169-177

Williamson P. Hennessy DP and Cutler R (1980) The use of progesterone and oestrogen concentrations in the diagnosis of pregnancy and in the study of seasonal infertility in sows Australian Joumal of Agricultural Research 31 233-238

Wilson MR and Love RJ (1990) The effect of the presence of older females on the maintenance of pregnancy in gilts in the seasonal infertile period. In Proceedings of the Intemational Pig Veterinary Sociely. p. 442 Ed. Scientific Committee of 11th International Pig Sciences Society Fritz Weibel. Thun

Wrathall AE. Wells DE, Jones PC and Foulkes JA (1986) Seasonal variations in serum progesterone levels in pregnant sows Veterinary Record $118685-687$ 